\title{
Comparative Study of Ultrasound Guided Modified Rectus Sheath Block With Conventional Post-Operative Analgesia in Lower Abdominal Surgeries
}

\author{
Dr. Vatsal C Patel ${ }^{1}$, Dr. Kamla H Mehta ${ }^{2}$, Dr. Kirti D Patel ${ }^{3}$ \\ ${ }^{1}$ Consultant Anaesthesiology, Ahmedabad, Gujarat, India \\ ${ }^{2}$ Professor, Department of Anaesthesiology, Smt. N.H.L. Municipal Medical College, Ahmedabaad, \\ Gujarat, India \\ ${ }^{3}$ Professor, Department of Anaesthesiology, Smt. N.H.L. Municipal Medical College, Ahmedabaad, Gujarat, \\ India Institute: Department of Anaesthesiology, Smt. SCL General Hospital \\ Smt. NHL Municipal Medical College, Ahmedabad. 380018
}

\begin{abstract}
Aim of the study was to assess and compare the effect of the USG guided modified rectus sheath block (MRSB) with the conventional type of Post-operative analgesia in Lower Abdominal Surgeries. It is Prospective Randomized study. The Patients were randomly allocated in two groups. Group A were given USG guided rectus sheath block and Group B were given Inj Diclofenac Sodium 75mg iv. Patients with obesity, Local Anesthetic agent allergy and emergency surgeries were excluded. Pain was assessed at every hour for 24hrs postoperatively by visual analogue pain score. Postoperative pain was assessed by visual analogue pain score (VAS) at every hour for 24hrs postoperatively. The VAS was significantly lower in Group A at 6hrs postoperatively. There were no any complications noted. USG guided modified rectus sheath block (MRSB) is very effective in providing immediate postoperative analgesia than conventional type of postoperative analgesia.
\end{abstract}

Keywords: Lower Abdominal Surgeries, Post-operative analgesia, USG guided Modified Rectus Sheath Block (MRSB), VAS Score.

\section{Introduction}

Post-operative pain is usually under estimated and under treated, resulting into cardiovascular, respiratory and thromboembolic complications, increase hospital stay, impaired quality of Life and development of chronic pain syndrome (Level of Evidence 1a)[1].

The rectus sheath block was initially used for the purpose of relaxation of abdominal wall muscles before the adjunct of neuromuscular blocking drugs [2] but now it is used to provide analgesia after umbilical or incisional hernia repairs and other surgical incisions of midline. The aim of this technique is to block the terminal branches of the $9^{\text {th }}, 10^{\text {th }}$, and $11^{\text {th }}$ intercostal nerves which run in between the internal oblique and transversus abdominis muscles to penetrate the posterior wall of the rectus abdominis muscle and end in an anterior cutaneous branch supplying the skin of the umbilical area[3].

\section{Aims And Objective}

Aim of the study was to assess and compare the effect of the USG guided modified rectus sheath block (MRSB) with the conventional type of Post-operative analgesia in Lower Abdominal Surgeries.

\section{Material And Method}

Total 60 adult Patients of 18-40yrs of age and ASA grade I/II having 40-70kg weight were included in this study. After informed written consent routine pre-anaesthetic check-up of all patients and necessary investigation were carried out. Patients with Local abdominal wall infection, allergy to local anaesthetic drug and obese patients were excluded from the study.

Patients were kept NBM for 6 hours. All patients were given Tab. Alprazolam $0.5 \mathrm{mg}$ night before surgery. Patients of lower abdominal surgeries under general anaesthesia were randomly divided in two groups. Each group included 30 patients. After completion of surgery,

Group A were given USG guided Modified Rectus Sheath Block (MRSB) with Inj. Levobupivacaine $0.25 \% 20 \mathrm{ml}$ and Group B were given Injection Diclofenac $75 \mathrm{mg}$. I. V. postoperatively.

Pain was assessed every hourly for $24 \mathrm{hrs}$ for postoperative analgesia by a visual analogue pain score $(0=$ no pain, $10=$ severe pain). Pain was assessed by an independent observer blind to the patients grouping.

- Modified Rectus Sheath Block(MRSB):-

- Group A Patients were received MRSB under strict aseptic precautions 
- A linear Probe was placed transverse over Abdomen just below the umbilicus on either side of the midline.

- $\quad 23 \mathrm{G}$ spinal needle attached by flexible tubing to a $0.25 \%$ Levobupivacaine filled syringe was introduced in midline $2 \mathrm{~cm}$ below the Umbilicus. Move probe laterally and scan Rectus abdominis muscle in transverse plane.

- Insert Block needle in plane, the puncture point should be suitably lateral that the needle will have shallow trajectory.

- $\quad$ Aim to position the tip of the needle between the rectus abdominis muscle and posterior rectus sheath. Stop the needle tip just superficial to the first white line (posterior sheath) as 'pop' is not felt in all patients.

- Aspirate and inject $0.25-0.5 \mathrm{mls}$, if the tip is in correct plane the muscle is peeled off the posterior sheath. Deposit $20 \mathrm{ml}$ of $0.25 \%$ levobupivacaine in the potential space between the rectus abdominis muscle and posterior aspect of the sheath.

- $\quad$ Patient were watched and observed for specific complication like,

- Peritoneal puncture

- Perforation of bowel

- Visceral puncture

- Inferior Epigastric vessels puncture

- Retroperitoneal hematoma

- Conventional type:- Group B Patients were given conventional method of analgesia with Inj. Diclofenac sodium $1-2 \mathrm{mg} / \mathrm{kg} \mathrm{IV}$ at the end of the surgeries before transferring the patient to post operative ward and then after every 6 hourly. Post operative analgesia was assessed with Visual Analogue Scale (VAS)[4] at every 1 hour for 24 hours except when patient is sleeping (Consider VAS as 0-2).

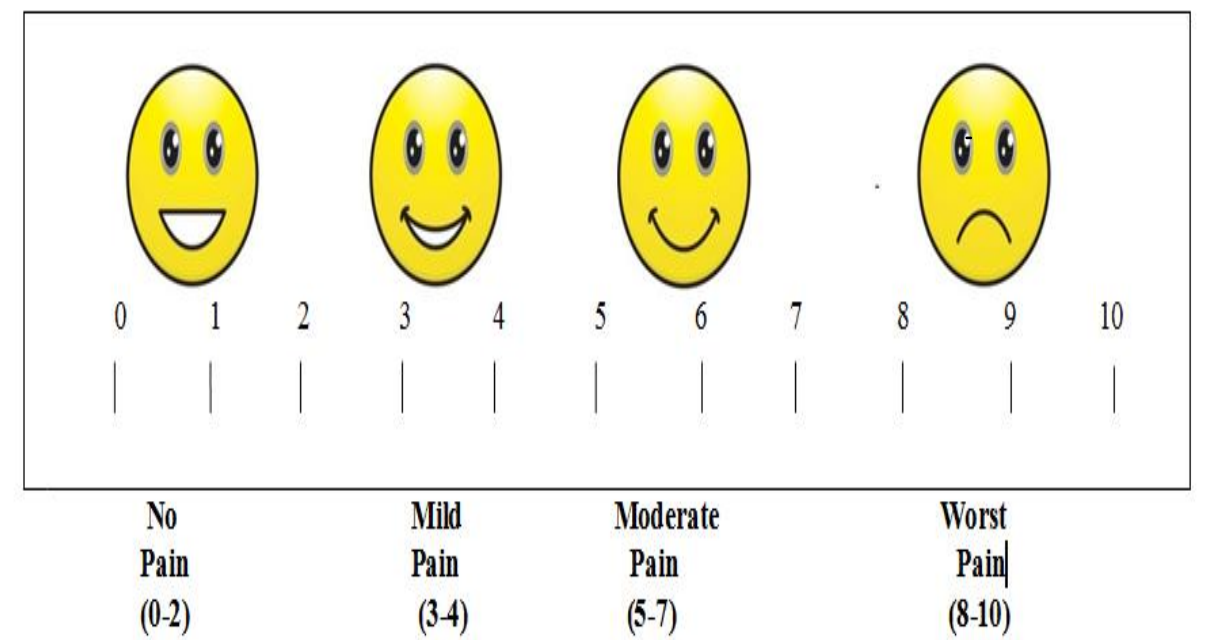

All the patients of both the groups were monitored for heart rate and Mean arterial blood pressure for every hour up to $24 \mathrm{hrs}$ postoperatively. However, the VAS Score compared for only $12 \mathrm{hrs}$ as patients of Group A were given only single injection of local anaesthetic drug for Modified Rectus Sheath Block. All the patients (Group A and Group B) were given inj. Diclofenac $75 \mathrm{mg}$ i.v. after $12 \mathrm{hr}$ for post operative analgesia. Statistical analysis was performed using Student's t-test and presented as mean \pm SD with $p$ value considered significant as $<0.05$.

\section{Results}

Total 60 patients were studied and the data were analyzed. 30 patients were given MRSB and 30 patients were given Intraperitoneal Instillation. There was no significant difference among the groups in Patients Demographic Data TABLE-1.

Table 1 Patients Demographic Data

\begin{tabular}{|l|l|l|}
\hline Demographic & Group A (MRSB) & Group B(IP) \\
\hline Age(yrs) & $27.2 \pm 5.03$ & $29.1 \pm 4.2$ \\
\hline Male: Female & $25: 5$ & $26: 4$ \\
\hline ASA I:II & $23: 7$ & $25: 5$ \\
\hline Weight(kg) & $63 \pm 12$ & $60 \pm 10$ \\
\hline Duration of operation(min) & $31 \pm 3.7$ & $30.5 \pm 2.09$ \\
\hline
\end{tabular}


Table 2 Visual Analogue pain Score (Mean + SD) in patients

\begin{tabular}{|l|l|l|l|l|}
\hline $\begin{array}{l}\text { Postoperative } \\
\text { assessment } \\
\text { period }\end{array}$ & $\begin{array}{l}\text { Group A } \\
(\mathbf{n = 3 0})\end{array}$ & $\begin{array}{l}\text { Group B } \\
(\mathbf{n = 3 0})\end{array}$ & $\begin{array}{l}\text { 'p' value } \\
\text { (S= significant) } \\
\text { (HS= Highly significant) } \\
\text { (NS= not significant) }\end{array}$ \\
\hline $1 \mathrm{hr}$ & $1.16 \pm 1.20$ & $1.83 \pm 0.74$ & 0.012 & S \\
\hline $2 \mathrm{hr}$ & $2.03 \pm 0.61$ & $2.50 \pm 0.50$ & 0.002 & HS \\
\hline $3 \mathrm{hr}$ & $2.00 \pm 0.58$ & $2.70 \pm 0.40$ & $<0.0001$ & HS \\
\hline $4 \mathrm{hr}$ & $2.80 \pm 0.60$ & $4.43 \pm 0.56$ & $<0.0001$ & HS \\
\hline $5 \mathrm{hr}$ & $2.76 \pm 0.62$ & $4.40 \pm 0.90$ & $<0.0001$ & HS \\
\hline $6 \mathrm{hr}$ & $3.13 \pm 0.62$ & $6.96 \pm 0.85$ & $<0.0001$ & HS \\
\hline $7 \mathrm{hr}$ & $3.13 \pm 0.62$ & $0.80 \pm 0.80$ & $<0.0001$ & HS \\
\hline $8 \mathrm{hr}$ & $4.73 \pm 1.83$ & $3.73 \pm 0.69$ & 0.007 & HS \\
\hline $9 \mathrm{hr}$ & $4.83 \pm 1.87$ & $3.83 \pm 0.69$ & 0.008 & HS \\
\hline $10 \mathrm{hr}$ & $6.16 \pm 1.41$ & $4.36 \pm 1.09$ & $<0.0001$ & HS \\
\hline $11 \mathrm{hr}$ & $2.23 \pm 1.83$ & $5.66 \pm 1.39$ & $<0.0001$ & HS \\
\hline $12 \mathrm{hr}$ & $1.06 \pm 0.82$ & $0.63 \pm 0.61$ & 0.020 & S \\
\hline
\end{tabular}

Mean duration of VAS Score was significantly lower $2.80 \pm 0.60$ in Group A as compared to $4.43 \pm 0.56$ in Group B at 4hr. At 6hrs, the mean of VAS Score was 3.13 \pm 0.62 in Group A while $6.96 \pm 0.85$ in Group B. First Rescue analgesic was given in Group A at $10 \mathrm{hrs}$ when the mean of VAS Score was $6.16 \pm 1.41$, while in Group B second dose of I. V. Diclofenac was given and again it was repeated at $12 \mathrm{hrs}$. The p value was $<0.0001$ at $4 \mathrm{hrs}, 6 \mathrm{hrs}$, and $10 \mathrm{hrs}$ as shown in TABLE-2.

\section{Discussion}

This study was carried out with the aim of evaluating and comparing Ultra Sonology Guided Modified Rectus Sheath block (USGMRSB) with injection Diclofenac for immediate post operative analgesia in 60 patients of lower abdominal surgery. The demographic data in terms of age, weight, sex, and ASA grade were comparable in both the groups of our study TABLE-1. There were almost equal numbers of patients who underwent surgeries in both the groups.

Postoperative pain in most of the laparoscopic surgery is arising mainly from the abdominal wall and stretching of the parietal peritoneum. The central portion of the anterior abdominal wall is innervated by the ventral branches of the thoracolumbar nerves (T6-L1) which are located deep to the Rectus abdominis muscle but anterior to its posterior sheath. A spread of local anesthetic solution is possible in this potential space as tendons of Rectus muscle are not attached posteriorly and US guided Rectus sheath block is recommended for postoperative analgesia for midline incisions on abdominal wall[4].

Effective management of postoperative pain of anterior abdominal wall after abdominal surgery contributes to early patient's recovery. Post-operative pain is usually under estimated and under treated, resulting into Cardiovascular, Respiratory and ThromboEmbolic complication, increase hospital stay, impaired quality of Life and Development of Chronic pain syndrome (Level of Evidence 1a)[1].

Injection Diclofenac I. V. six hourly is routinely used for postoperative analgesia in surgical ward and hence we have compared it with the USGMRSB for immediate postoperative analgesia.

Smith BE[5] et al, studied BRSB in diagnostic laparoscopy and compared with control group. They used $15 \mathrm{ml}$ of Bupivacaine $0.25 \%$ at the end of the operation. They found block was significantly effective at 1 , 6 and $10 \mathrm{hrs}$ postoperatively as compared to control group.

Simin Azemati[6] al, compared rectus sheath block with intraperitoneal instillation and incisional infiltration and they found that rectus sheath block was producing prolonged analgesia (24hrs) as compared to intraperitoneal instillation and incisional infiltration. They had given block before incision with IV premedication. The duration of postoperative analgesia was prolonged than our study. This may be due to use of pre-emptive analgesia i.e before incision.

Sumitra Bakshi[7] et al used USGRSB as an alternative method to provide post operative analgesia in their case series and concluded that USGRSB with catheterisation can be feasible and effective pain management technique for midline laparotomy and can be considered when epidural analgesia is not a suitable option. 
The rectus sheath, which encloses the rectus muscle, extends from the xiphoid and $5^{\text {th }}-7^{\text {th }}$ costal cartilages to pubic crest. A rectus sheath block consists of a blockade of lower thoracic nerves (T7-T12). Bilateral rectus sheath block has been used successfully for the repair of umbilical and paraumbilical hernias in paediatric surgrey[8]. In diagnostic laparoscopy there is less cutting and manipulation of visceral organs so blockade of the lower thoracic nerve by MRSB is more effective in reducing pain. There were no complications like peritoneal puncture; Perforation of bowel, visceral puncture, retroperitoneal haematoma, inferior Epigastric vessel punctures.

\section{Conclusion}

From our study we comclude that USGMRSB is easy to performed, safe and less time consuming technique to provide prolonged immediate post operative analgesia than conventional type in patients of lower abdominal surgeries.

\section{References:}

[1]. Clinical practice guideline approved by Korean knee society on Feb $28^{\text {th }} 2012$ nih.gov KSSR knee surgery and related research. Open access Article sited on $24^{\text {th }} \mathrm{Feb} 2014$.

[2]. Willschke $\mathrm{H}$, Bosenberg A, Marhofer $\mathrm{P}$ et al. Ultrasonography-guided rectus sheath block in paediatric anaesthesia - a new approach to an old technique. Br J Anaesth 2006; 97: 244-9.

[3]. J Yarwood MBChB FRCA A Berrill MBChB FRCA. Nerve blocks of the anterior abdominal wall: Continuing Education in Anaesthesia, Critical Care \& Pain Advance Access published September 10, 2010

[4]. Gillian A. Hawker, Samra Mian, Tetyana Kendzerska and Melissa French. Arthritis Care \& Research Vol. 63, No. S11, November 2011, pp S240-S252.

[5]. Smith BE, Suchak M, Siggings D et al. Rectus sheath block for diagnostic laparoscopy. Anesthesia . 1988;43:947-8.

[6]. Simin Azmeti, M.B. Khosravi. An assessment of the value of rectus sheath block for post laparoscopic pain in gynaecologic surgery. Journal of Minimally Invasive Gynecology (2005) 12, 12-15.

[7]. Sumitra Bakshi, Amol mapari, Rohit Paliwal: Ultrasound guided rectus sheath catheters: A feasible and effective, opioid sparing, postoperative pain management technique: Indian journal Anaesthe.2015 Feb; 59(2):118-120

[8]. Sandeman DJ, Dilley AV. Ultrasound - guided rectus sheath block and catheter placement. ANZ Journal of Surgery 2008; 78:621-3. 